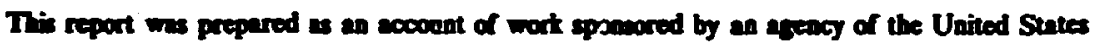

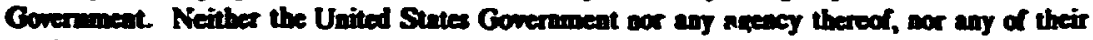

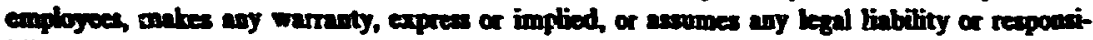

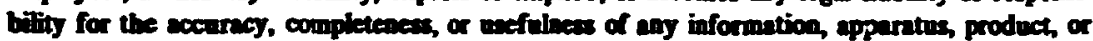
proces disclowed, or reprewente that its we would not infringe privately owned rights Reference berein to any epecific commercial prodect, process, or ea vice by trede name, trademart,

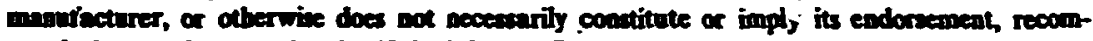
meadation, of favoring by the United States Government of an acency thereol. The viewe and opinions of anthore expresed berein do not necessarily state or reflect those of the United Sistes Coverumeat or any agency thereof.

\title{
SUPERCONDUCTING TOROIDAL FIELD COIL CURRENT DENSITIES FOR THE. TFCX
}

\author{
S. S. Kalsi \\ R. J. Hooper \\ Fusion Engincering Design Center- \\ General Electric Company \\ Date Published - April 1985
}

Prepared by

OAK RIDGE NATIONAL LABORATORY

Oak Ridge, Tennessee 37831

operated by

MARTIN MARIETTA ENERGY SYSTEMS, INC.

for the

U.S. DEPARTMENT OF ENERGY

under Contract No. DE-AC05-84OR21400 


\section{CONTENTS}

ABSTRACT $\ldots \ldots \ldots \ldots \ldots \ldots \ldots \ldots \ldots \ldots \ldots \ldots \ldots \ldots \ldots \ldots \ldots \ldots \ldots$

1. INTRODUCTION AND SUMMARY $\ldots \ldots \ldots \ldots \ldots \ldots \ldots \ldots \ldots \ldots$,

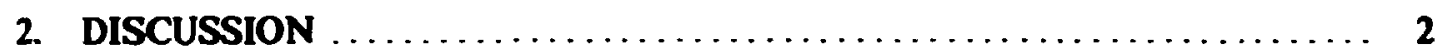

2.1 FEASIBILITY OF GRADING FORCED-FLOW WIND!NGS ........ 2

2.2 AVERAGE WINDING CURRENT DENSITY VERSUS

CONDUCTOR CURRENT $\ldots \ldots \ldots \ldots \ldots \ldots \ldots \ldots \ldots \ldots \ldots \ldots \ldots$

2.3 ANALYSIS OF CRITICAL CURRENT DATA ........... 5

2.4 EFFECT OF CONDUCTOR GRADING ON CURRENT DENSITY ..... 9

2.5 PERMISSIBLE NUCLEAR HEAT VERSUS COOLING

SYSTEM PARAMETERS $\ldots \ldots \ldots \ldots \ldots \ldots \ldots \ldots \ldots \ldots \ldots \ldots \ldots$

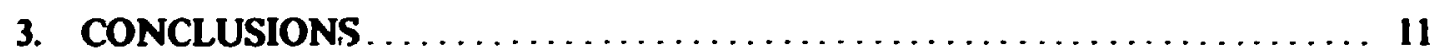

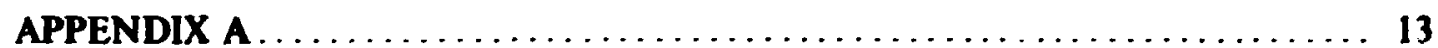

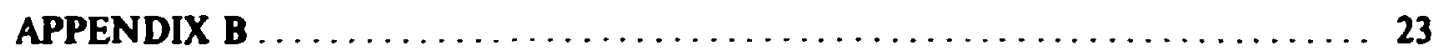

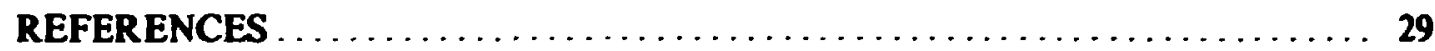




\begin{abstract}
A major goal of the Tokamak Fusion Core Experiment (TFCX) study was to min . imize the size of the device and achieve lowest cost. Two key factors influencing the size of the device employing superconducting magnets are torcidal field (TF) winding current density and its nuclear heat load withstand capability. Lower winding current density requires larger radial build of the wirding pack. Likewise, lower allowable nuclear heating in the winding requires larger shield thickness between the plasma and coil. In order to achieve a low-cost device, it is essentiai to maximize the winding's current density and nuclear heating withstand capability. To meet the above objective, the TFCX design specification adopted as goals a nominal winding current density of $3500 \mathrm{~A} / \mathrm{cm}^{2}$ with $10-\mathrm{T}$ peak field at the winding and peak nuclear heat load limits of $1 \mathrm{~mW} / \mathrm{cm}^{3}$ for the nominal design and $50 \mathrm{~mW} / \mathrm{cm}^{3}$ for an advanced design. This study developed justificgtion for these current density and nuclear heat load limits.

A value of $3500 \mathrm{~A} / \mathrm{cm}^{2}$ is about $75 \%$ higher than values used in past studies and is based on evaluation of a variety of approaches. The approaches include consideration of (1) use of forced-flow $\mathrm{Nb}_{3} \mathrm{Sn}$ conductors, similar to the Westinghouse Large Coil Program (LCP) conductor; (2) epoxy impregnation of the winding, which alters the load path and permits elimination of the co-wound structural material; (3) designing to $80 \%$ of critical current instead of $67 \%$, as previously done; (4) reacting the conductor after winding to anneal out induced strains; and (5) use of Incoloy instead of JBK-75 as the conduit. Incoloy has cooldown characteristies that closely match that of the $\mathrm{Nb}_{3} \mathrm{Sn}$, so the induced cooldown strain is decreased.

In the nominal design, the $\mathrm{Nb}_{3} \mathrm{Sn}$ conductor employs JBK-75 stainless steel conduit with a thickness of $1.7 \mathrm{~mm}$ and a void fraction inside the condut of $32 \%$. Peak nuclear heat load of $1 \mathrm{~mW} / \mathrm{cm}^{3}$ can be removed by forced-flow helium entering at $4.2 \mathrm{~K}$ and exiting at $4.5 \mathrm{~K}$. In the advanced design, with peak nuclear heating of $50 \mathrm{~mW} / \mathrm{cm}^{3}$, the reasonable winding exit temperature is $5.5 \mathrm{~K}$. To of set the degradation in critical curren! at the higher temperature, the void fraction is increased to $41 \%$ (from $32 \%$ ) and an Incoloy conduit is used (in place of the JBK-75 conduit). The resulting conductor crosssectional dimensions change slightly, but the winding current density remains about the same $\left(3500 \mathrm{~A} / \mathrm{cm}^{2}\right)$.

This study concludes hat the specified TF winding current densities ire an aggressive step forward but are realistically achievable using existing forced-flow, cable-in-conduit conductor or its variations.
\end{abstract}




\section{INTRODUCTION AND SUMMARY}

During the development of the Tokamain Fusion Core Experiment (TFCX) superconducting toroidal field (S/C TF) coil options, there has been strong motivation to limit the radial build of the device in the centerpost region, because it is generally agreed that, to a first approximation, the cost of the device varies with the plasma major radius $\boldsymbol{R}_{\boldsymbol{o}}$ to a power between 2.5 and 3.0. Methods for achieving a compact device include designing the TF coils for a high winding current density and a high nuclear heat load, the latter permitting a reduction in the inboard shield thickness. The conductor critical current is enhanced by lowering the operating temperature, whereas increased nuclear heat loads tend to lead to increased conductor temperatures. Consequently, the objectives of high current density and high nuclear heat are mutually conflicting.

The example problems considered in this study assume use of a $\mathrm{Nb}_{3} \mathrm{Sn}$ forced-ilow conductor similar in size and void fraction to the Westinghouse Large Coil Program (LCP) conductor. Most of the examples considered in this study assume use of a single grade of conductor throughout the winding. A few examples have been worked to illustrate the potential gains in average current density afforded by grading, but methode of grading forced-flow conductors are not well developed, and the practicality of such grading is considered doubtful.

With a single grade of conductor, the TFCX design specification ${ }^{1}$ winding current density of $3500 \mathrm{~A} / \mathrm{cm}^{2}$ at $10 \mathrm{~T}$ can be met using the present Westinghouse LCP conductor (with JBK-75 conduit), provided the conductor operating temperature is suitably controlled. If the conductor is reacted before winding, the maximum acceptable conductor temperature is $4.5 \mathrm{~K}$. For a TFCX application, this limit can be satisfird with a reasonably straightforwa: 1 helium manifolding arrangement, if the nuclear heat load does not exceed $1 \mathrm{~mW} / \mathrm{cm}^{3}$ (nominal design requirement). If the conductor is reacted after winding, a peak conductor operating temperature of $5.5 \mathrm{~K}$ is accsptable. At $12 \mathrm{~T}$, the $2300-\mathrm{A} / \mathrm{cm}^{2}$ design specification can be met with this conductor only if the conductor is reacted after winding and operated at a temperature of $4.2 \mathrm{~K}$ or lower.

If the JBK-75 sheath is replaced by an Incoloy 903 sheath, the cooldown contraction of the conductor composite closely approximates that of $\mathrm{Nb}_{3} \mathrm{Sn}$, so that the degradation of the critical current due to cooldown strain is greatly reduced. The absence of significant cooldown-induced degradation has been demonstrated by the Massachusetts Institute of Technology (MIT) in short-sample tests. On this basis, the achievable current density as a function of peak conductor temperature at $10 \mathrm{~T}$ and at $12 \mathrm{~T}$ may be sunumarized as shown in Fig. 1. It is clear that use of Incoloy in place of JBK-75, or use of the wind-and-react technique, increases the maximum temperature at which the design specification current Gensity can be achicved; this implies increased freedom of design with respect to allowable nuclear heat and coolant manifolding arrangement.

With respect to maximum permissible nurlear heat loads, it is found that for practical helium manifolding arrangements (e.g., winding three-in-hand, a flow path length of four turns is about $72 \mathrm{~m}$ ), approximately 10 to $12 \mathrm{~mW} / \mathrm{cm}^{3}$ may be tolerated purely from a heat-removal standpoint. For more complex m nifolding arrangements (e.g., cooling one turn or one-half turn in regions of peak nuclear heat), up to about $100 \mathrm{~mW} / \mathrm{cm}^{3}$ becomes psssible. However, these nuclear heat loads entail conductor temperatures up to about $6 \mathrm{~K}$, 


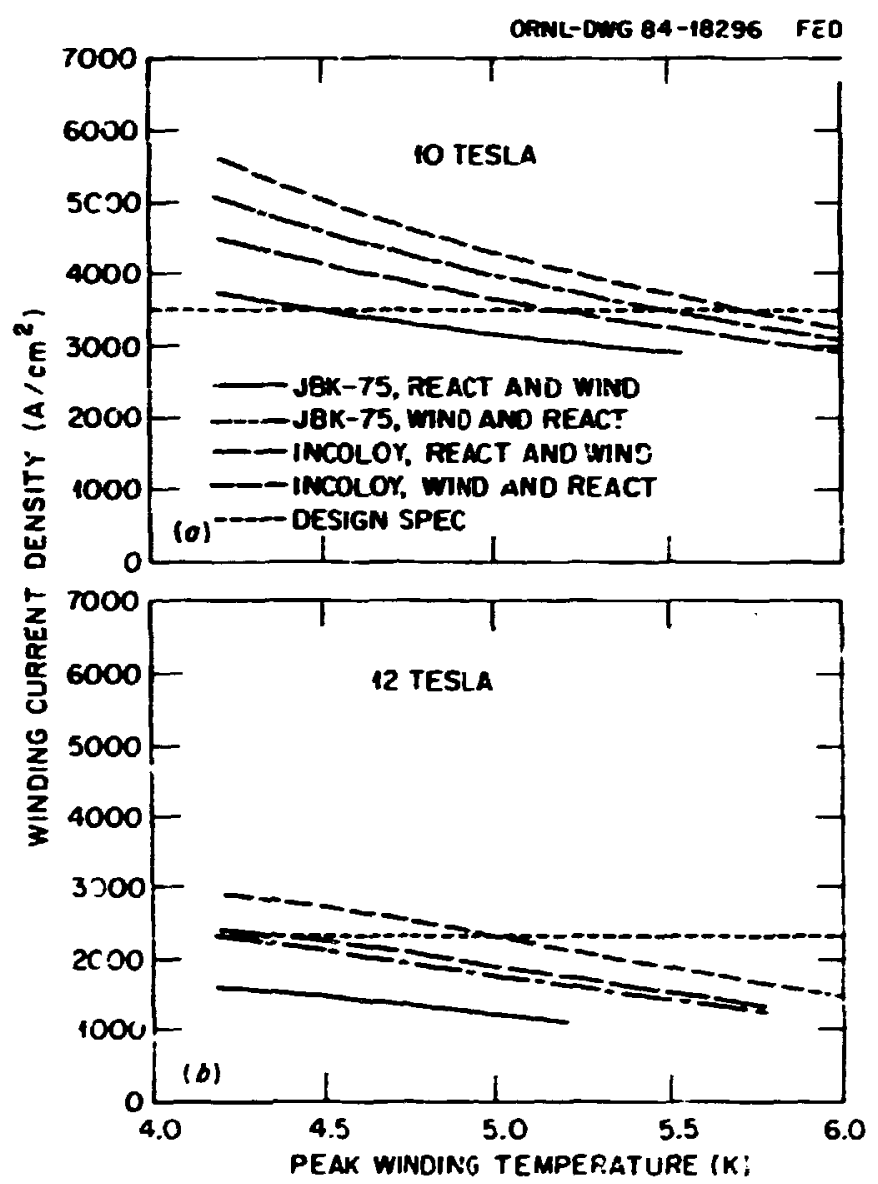

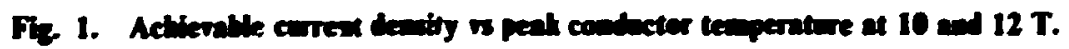

which would degrade the critical current to the point at which the design specificatior. current densities could not be met.

The assumptions, design criteria, and equations used in the supporting analysis are included in Appendix A.

\section{DISCUSSION}

\subsection{FEASIBILITY OF GR,ADING FORCED-FLOW WINDINGS}

If a forced-flow winding is designed to have the same current in all turns, grading requires a transition in conduit cross section when changing from one conductor grade to another. Joint dcsigns for achieving such cross-section transitions have not yet been developed and demonstrated.

On the other hand, if the conduit cross section is maintained throughout the winding. grading requires different current in each grade. This type of design requires separate 
power supplies and cryogenic leads for each grade. This increases complexity of the winding configuration in order to bring these leads out of the conductor pack. Such a design approach represents a large increase in complexity for a next-step device, and, in any event, the additional cost resulting from the complexity of these additional leads and power supplies must be weighed against the cost benefits associated with the higher average current density. While grading is not out of the question, it is far from being a state-ofthe-art design technique for forced-flow windings. Consequently, the assumption of a graded winding for a near-term device is considered premature and overly optimistic.

\subsection{AVERAGE WINDING CURRENT DENSTTY VERSUS CONDUCTOR CURRENT}

This study assumes use of a $\mathbf{N b}_{3} \mathrm{Sn}$ conductor having a void fraction of $32 \%$ and a cross-sectional area insice the conduit of $2.93 \mathrm{~cm}^{2}$. These are the parameters associated with the Westinghouse LC: condustor (Fig. 2). Variations in the Westinghouse/Airco

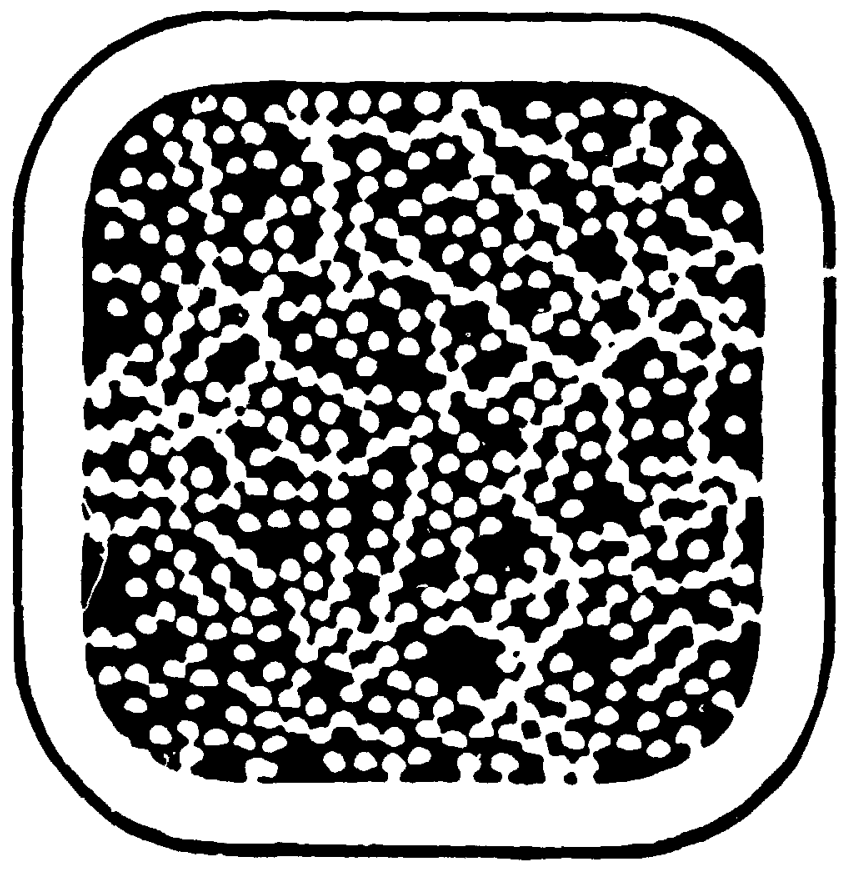

$\begin{array}{ll}\text { CONDUCTOR IIMENSION OUTSIDE CONDUIT } & 2.19 \mathrm{~cm} \\ \text { CONDUIT THICKNESS } & 1.70 \mathrm{~mm} \\ \text { CROSS SECTIONAL AREA INSIDE CONDUIT } & 2.93 \mathrm{~cm}^{2} \\ \text { VOIO FRACTION } & 32 \% \\ \text { NUMBER OF STRANDS } & 1458 \\ \text { STRAND DIAMEIER } & 0.70 \mathrm{~mm} \\ \text { HYORAULIC OIAMETER } & 0.40 \mathrm{~mm}\end{array}$

Fie. 2. Weatinghome LCP coil condector. 
values of conduit wall thickness, conduit corner bend radius, conduit material, and heat treatment are considered.

Figure 3 shows the average winding current density compared to conductor current for a design developing a peak field of $10 \mathrm{~T}$ at a radius of $1.7 \mathrm{~m}$ [representative of an early TFCX-S (all-superconducting TF coil) design]. Figure 4 shows a similar curve for a 12-T reak field at a radius of $2.4 \mathrm{~m}$. In each of these designs, a single grade of conductor is used.

The 10-T examples use a conduit thickness of $2 \mathrm{~mm}$ (compared to $1.7 \mathrm{~mm}$ in the Westinghouse LCP) and an inside surface corrier bend radius of $4 \mathrm{~mm}$ (versus $2.85 \mathrm{~mm}$ in the Westinghouse LCP), whereas the 12-T examples use a jacket thickness of $3 \mathrm{~mm}$ and an inside surface bend radius of $6 \mathrm{~mm}$. These values were selected on the basis of a structural analysis routine described in Appendix A. This analysis routine considers the combined stress state in the conduit wall due to transverse compressive winding loads and longitudinal dilational tensile loads. A conduit wall thickness is selected to meet established structural design criteria, to withstand realistic quench pressures, and to conform to conduit thickness limitations related to manufacturing considerations.

The selection of the actual conductor operating current depends upon the critical current, which is a function of many variables:

- maximum field;

- residua! compressive cooldown strain in lie conductor;

- choice of jacket material and heat treatment, both of which affect the residual cooldown strain;

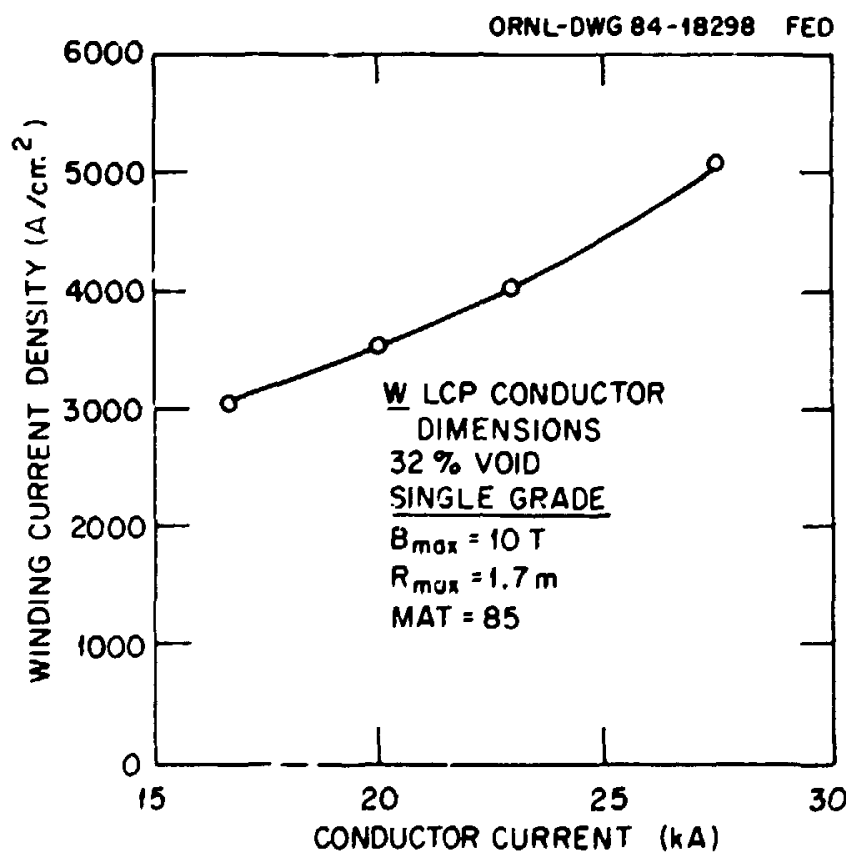

Fig. 3. Arerage curreat dendity is conductor cerreat at $10 \mathrm{~T}$. 


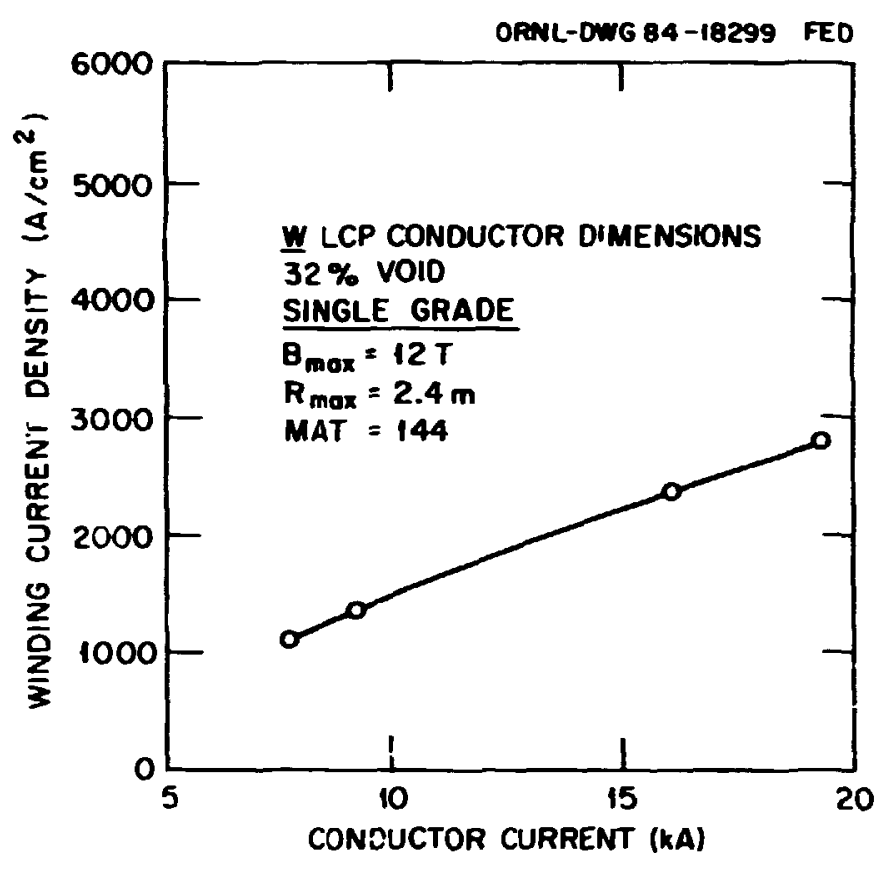

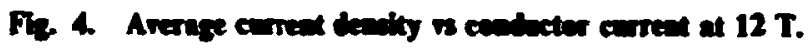

- strain level in conductor from beirg bent into the minimum radius of curvature during coil winding, which can be relieved if the conductor is reacted after winding; and

- strain level in conductor resulting from operating loads.

Determination of an appropriate operating current, and the average winding current density resulting from that choice, are discussed in Sect. 2.3.

\subsection{ANALYSIS OF CRITICAL CURRENT DATA}

Figure 5, which is reproduced from ref. 2, shows the critical current of $4.2 \mathrm{~K} s 2 \mathrm{mples}$ of Westinghouse LCP conductor as a function of imposed tensile strain, for field levels of 8,10 , and $12 \mathrm{~T}$. This conductor uses a JBK-75 conduit and is reacted for $31 \mathrm{~h} \mathrm{~h}$ at $700^{\circ} \mathrm{C}$.

At the $10 \%$ field, the critical current is $24 \mathrm{kA}$ with no imposed tensile strain and reaches $41 \mathrm{kA}$ for an imposed tensile strain of $0.75 \%$. The $0.75 \%$ imposed strain is therefore equal and opposite to the residual compressive strain due to cooldown plus winding; MIT has determined that the cooldown portion alone is $-0.5 \%$. A compressive strain of $0.75 \%$, therefore, degrades the critical current to $59 \%$ of its value in the strain-free state (24 vs $41 \mathrm{kA}$ ). This fractional degradation is in reasonably good agreement with Ekin's strain raling law given in ref. 3:

$$
\frac{I}{I_{0}}=\sqrt{1-a|\ell|^{1.7}} \quad\left[\frac{1-\frac{B}{22\left(1-a|\epsilon|^{1.7}\right)}}{1-B / 22}\right]^{2} \text {, }
$$




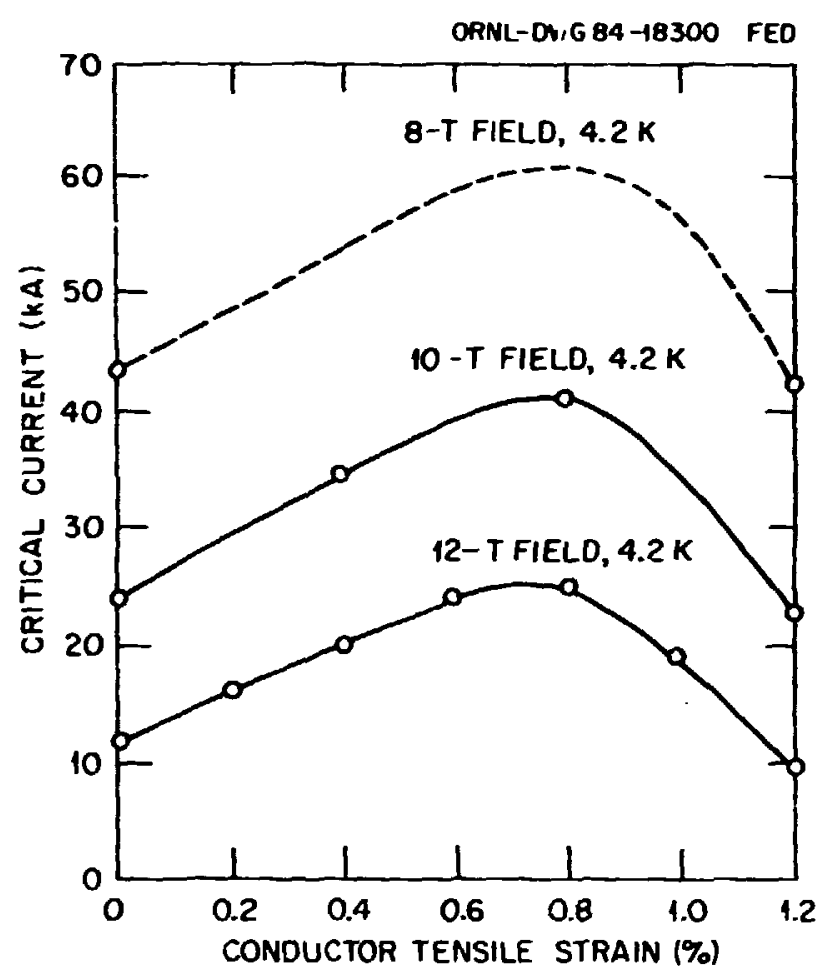

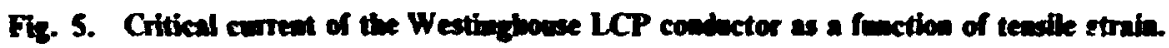

where $\epsilon$ is the strain, $a=900$ if $\epsilon<0$, and $a=1250$ if $\epsilon>0$. For $\epsilon=-0.0075$ and $B=10 \mathrm{~T}$, Eq. (1) gives $I / I_{0}=0.52$.

For a TFCX-size coil, th:s minimum radius of curvature imposed on the conductor during coil winding is about $1.5 \mathrm{~m}$, corresponding to a bending strain in the conduit wall of about 0.7\%. According to ref. 2 (vol. VI, Part 1, pp. 7-55), the strands experience about one-third the bending strain developed in the conduit, or about $0.23 \%$. Furthermo:e, when the coil is energized, a dilational tensile strain of about $0.1 \%$ is developed. Thus, the net strain, including cooldown strain, is $-0.50-0.23+0.10=-0.63 \%$. Ekin's formula with $\epsilon=-0.0063$ and $B=10 \mathrm{~T}$ gives $I / I_{o}=0.64$. Under TFCX conditions, the critical current at $10 \mathrm{~T}$ becomes $0.64 \times 41=26.3 \mathrm{kA}$ at $4.2 \mathrm{~K}$.

The maximum conductor temperature depends upon the amour,t of nuclear heat that the coil must withstand. A separate analysis has shown that for $1 \mathrm{~mW} / \mathrm{cm}^{3}$ (the nominal design value per ref. 1), a temperature rise of about $0.5 \mathrm{~K}$ occurs. Reference 4 predicts that the critical current at temperature $T$ degrades from its $4.2 . \mathrm{K}$ value by the fraction

$$
\frac{I_{c}(B, T)}{I_{c}(B, 4.2)}=1-\frac{T-4.2}{10.7-0.61 B}
$$


If helium enters at $4.0 \mathrm{~K}$ and exits at $4.5 \mathrm{~K}$, then for $B=10 \mathrm{~T}$, Eq. (2) gives a fractional degradation of 0.935 , so that the crivical current at $4.5 \mathrm{~K}$ is $24.6 \mathrm{kA}$. If the conductor current is set at $\mathbf{8 0 \%}$ of the critical current, it follows that the Westinghouse LCP conductor, without modification, would operate in a TFCX application at $19.7 \mathrm{kA}$ at $10 \mathrm{~T}$. This corresponds to an average current density (with a single grade) of $3500 \mathrm{~A} / \mathrm{cm}^{2}$, which just meets the design specification.

One way to increase the critical current of the Westinghouse LCP conductor (with the present JBK-75 sheath material) is to react the conductor after winding. This process anneals out the strain introduced during winding, although cooldown compressive strain and tensile strain due to dilation remain during coil operation.

The feasibility of winding and reacting TFCX-size TF coils has been discussed with the Westinghouse LCP team. The principal technical feasibility issue is to identify an insulator wrap material that can survive the reacting temperature so that it would not be necessary to clean oxides off the reacted conductor and then apply insulating wrap after reacting. Furnaces large enough to react such large coils are considered technically feasible.

The critical current for wound-and-reacted, JBK-75-wrapped Westinghouse LCP conductor at $4.2 \mathrm{~K}$ is estimated by scaling down the peak critical current of $41 \mathrm{kA}$ (with zero strain) by the degradation per Eq. (1) for $B=10 \mathrm{~T}$ and $\epsilon=-0.0050$ (cooldown) + 0.001 (dilation) $=-0.0040$; the result is $I_{c}=34.2 \mathrm{kA}$. Since an operating current of $19.7 \mathrm{kA}$ is needed to achieve $3500 \mathrm{~A} / \mathrm{cm}^{2}$, th: critical current must not go below $24.6 \mathrm{kA}$. Therefore, a temperature degradation of $24.6 / 34.2=0.72$ is acceptable when the conductor is reacted after winding; this corresponds to a peak conductor temperature of $5.5 \mathrm{~K}$.

References 5-7 describe recent work performed at MIT dealing with the effect on critical current of using different heat treatments and/or substituting Incoloy 903 for JBK-75 as the zonduit material. Figure 5 summarizes critical current data gathered from refs. 2 and 5-\{ and from conversations with MIT personnel. All of the data shown in Fig. 5 are for $42 \mathrm{~K}$ operation and therefore include the effects of cooldown strain.

There is a tramatic difference between the short-sample $(10-\mathrm{cm})$ and the long-sample (375-im) MIT Jata for JBK-75, although the long-sample results are not significantly different from the Westinghouse data. It would therefore appear that the MIT dual heat treatment in itsilf has a relatively minor impact on critical current and that the difference between short-sitmple and long-sample resuits for JBK-75 is due to effects related to specimen length.

One possible explanation is better transfer of heat away from the hot spot in the short samples, with an attendant increase in critical current. Another plausible explanation is that the short simples do not have adequate end restraint to simulate a plane strain condition. If the strands are not fully constrained to have the same longitudinal cooldown strain as the conduit, the short-sample results would then reflect little or, perhaps, no degradation due to cooldown strain.

At the 10-T field, the long-sample and short-sample critical currents for the dualheat-treated speimens are in the ratio $25 / 36.75=0.68$. If it is assumed that the shortsample critical i, urient approximates the as-reacted current, the observed degradation is equivalent to a rooldown strain of 0.0059 per Eq. (1). This strain estimate compares well with the value $0.006:$ Jetermined by analysis and reported in ref. 3. Therefore, it appears 
reasonable to conclude that the dual heat treatment of the JBK-75-wrapped cor.Juctor in itself offers no significant improvement over the Westinghouse/Airco heat treatment.

The short-sample curves in Fig. 6 show that use of Incoloy 903 in place of JBK-75 offers a modest increase in critical current at fields of $10 \mathrm{~T}$ and higher. More importantly, however, the cooldown contraction of the Incoloy-wrapped conductor closely matches the cooldown contraction of $\mathrm{Nb}_{3} \mathrm{Sn}$, so that the degradation due to cooldown contraction is small. ${ }^{7}$ The short-sample Incoloy 903 curve in Fig. 6 was used for the calculations.

At $10 \mathrm{~T}$, the critical current of an Incoloy 903-wrapped conductor (at $4.2 \mathrm{~K}$ with cooldown strain only) is therefore taken as $37.5 \mathrm{kA}$. In the absence of a significant cooldown strain, the degradation of critical current may be estimated using Eq. (1) with $\epsilon=$ 0.0023 (bending) +0.0010 (dilation) $=+0.0033$; the result is $I / I_{0}=0.835$. If, as before, an operating current of $19.7 \mathrm{kA}$ is needed to achieve $3500 \mathrm{~A} / \mathrm{cm}^{2}$, the required critival current of $24.6 \mathrm{kA}$ can be attained under these conditions with a temperature degradation

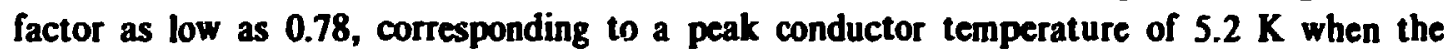
conductor is reacted before winding. In like manner, if the conductor is reacted after winding, the winding strain disappears and the maximum conductor temperature can be as high as $5.7 \mathrm{~K}$.

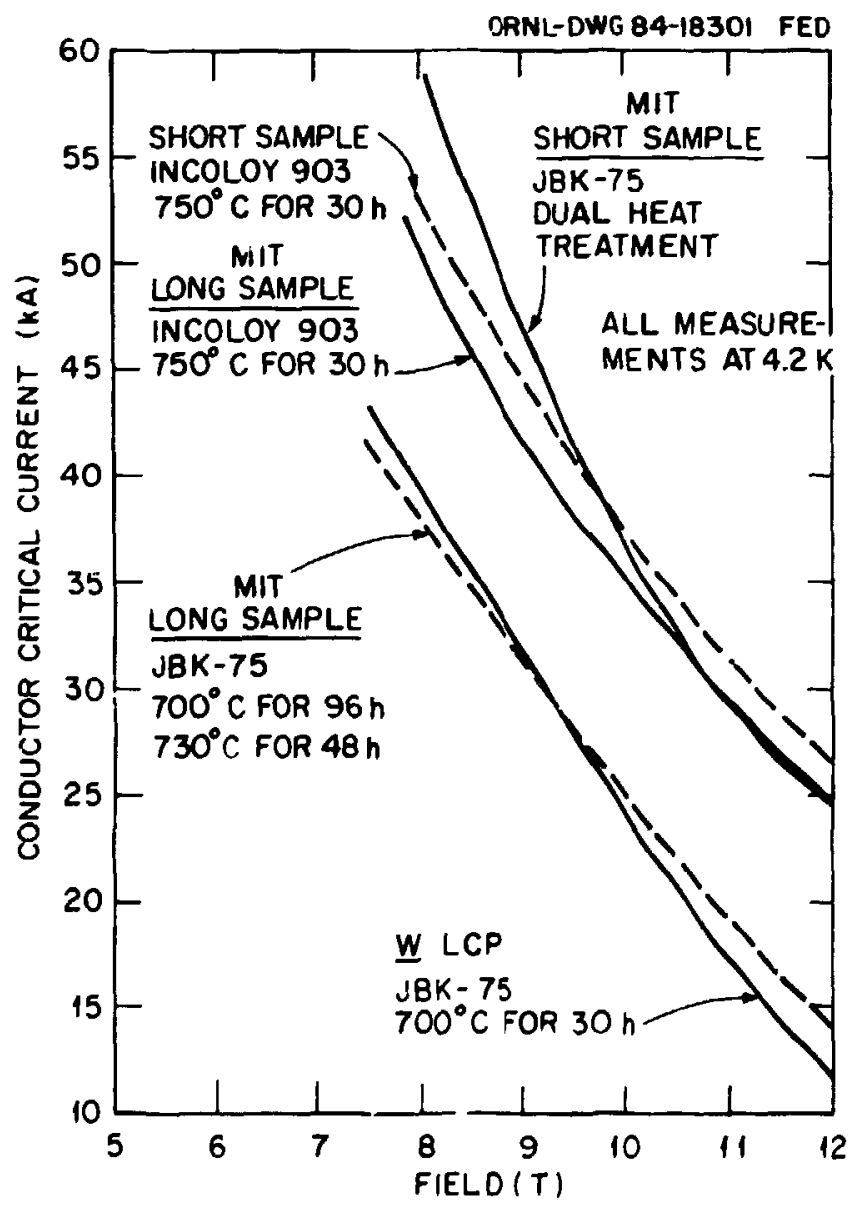

Fig. 6. Cable-in-cow iult (32\% rold) conductor current is field. 
A similar analysis of the critisal current data has been made for each of the combinations of possible conditions:

- JBK-75 or Incoloy jacket (affects cooldown strain),

- reart-and-wind or wind-and-react (aí. ts winding strain), and

- 10 or 12-T peak field.

Figure I summarizes the attainable current density as a function of peak conductor temperature for each combination of peak field, jacket material, and manufocturing sequence. The design specification current densities are shown for comparison. The curves afford a convenient method of comparing the current fessities that resuit from eacb possible combination. The higher the maximum acceptable conductor temperature, the greater the freedom of design with respect to nuclear heat and helium manifolding arrangement.

\subsection{EFFECT OF CONDUCTOR GRADING ON CURRENT DENSTIY}

Although the practicality of grading forced-flow windings is perhaps questionable, the analytic formalism described in Appendix $A$ includes the capability to model graded windings in which the conduit cross section is maintained and different currents are used in each grade.

Several cases were run to assess the potential increase in curient density afforded by grading. No attempt was made to address how leads woild be brought out of the winding.

Windings were sized to develop $12 \mathrm{~T}$ at a radius of $2.4 \mathrm{~m}$. Up to three grades were considered, with currents set at two-thirds of the critical currents shown in Fig. 6 on the curve labeled "W LCP." Corrections for temperature and winding strain effects were not considered in this evaluation, but the relative average current densities should be nonetheless indicative of the potential benefits of grading, if indeed grading is deemed practical. The operating currents and field ratings of the various grades are summarized in Table 1.

The results for a 12-T winding pack are summarized in Table 2. Use of two grades raises the average current density about $50 \%$ above that with a single grade, whereas use of three grades about doubles it.

Table 1. Combetiog operaties curreats and frebl rattaps

\begin{tabular}{lccc}
\hline & Grade 1 & Grade 2 & Grade 3 \\
\hline Operating current, kA & 28.7 & 16.7 & 7.7 \\
Maximum field, T & 8.0 & 10.0 & 12.0 \\
\hline
\end{tabular}




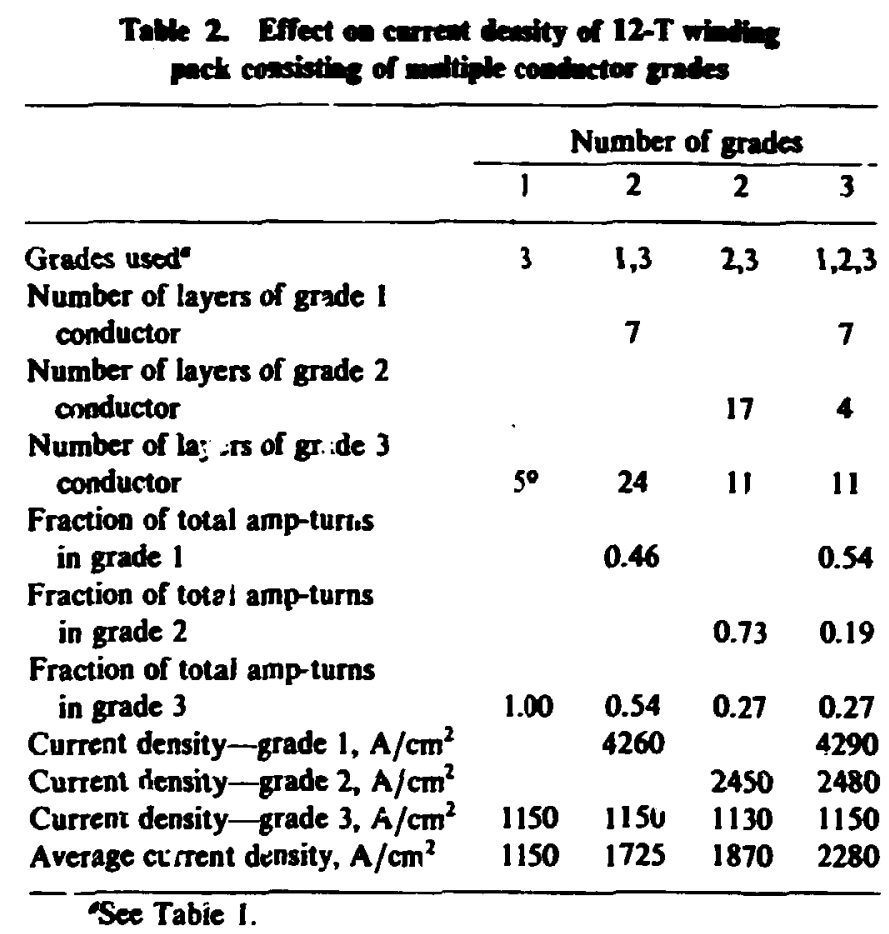

\subsection{PERMISSIBLE NUCLEAR HEAT VERSUS COOLING SYSTEM PARAMETERS}

As the nuclear heat load rises, more and more helium riust be circulated. Not only does this increasing mass flow increase pressure drops, but also the associated frictional i,eating increases the heat load further. In conventional piping system designs, these frictional heat terms are negligible, but in cryogenic systems, they are of the same order of magnitude as the imposed heat load. These heat loads limit the length of the coolant path and therefore affect the required number of coolant lines.

The aetermination of permissible nuclear heat loads was performed some time ago, using a representative TF coil design that differs somewhat from the cases discussed in the previous section. The $I T$ coil design studied here develops a peak field of $10 \mathrm{~T}$ using a single grade of conductor and operates at a winding current density of about $2850 \mathrm{~A} / \mathrm{cm}^{2}$. The conductor is a forced-flow design with $32 \%$ void fraction and a cross-sectional area inside the conduit of $5.2 \mathrm{~cm}^{2}$ (versus $2.93 \mathrm{~cm}^{2}$ in the Westinghouse LCP). The conduit thickness is $3 \mathrm{~mm}$, and the inside corner bend sadius is $6 \mathrm{~mm}$. The radial build of the TF winding is 12 turns.

Several coolant path lengths, corresponding to different manifolding arrangements, were considered. For each selected path length, the assumed nuclear heat load was gradually increased until it becams impossible to sele et inlet helium conditions that would result in acseptable pressure drops and helium exit temperatures of $6 \mathrm{~K}$ or less.

Helium outlet conditions were calculated using a computer program that accounts for spatial variation of ine nuclear heat load around tive perimeter of the TF coil and also 
accounts for attenuation of the nuclear heat load turn-to-turn. Pressure drops and frictional heat are calculated using the friction factor correlation in ref 2. The program csnthins thermodynamic properties of helium as defined in ref. 9.

A mean TF coil perimeter of $18 \mathrm{~m}$ was assumed, and coolant paih lengths of $1 / 2,1$, and 4 turns were considered. The TF coil configuration has a radial build of 12 turns, and if it is assumed that the coil is wound three-in-hand, a path length of 4 turns is considered about as sirfple a manifolding scheme as is reasonably achievable. The shorter path lengths represent more complex manifclding but offer the potential for higher incident nuclear heat.

All of the cooling system configurations considered here assume steady-state operation of the coil. Larger incident nuclear heat loads are perhaps feasible in pulsed machines by using a buffer helium supply that is allowed to boil during coil operation and is reliquefied between pulses.

Table 3 summarizes the maximum nuclear heat capability for three cooling system configurations (denoted A, B, and C) that differ in flow path length and in helium inlet and outlet conditions. A nuclear heat level of 10 to $12 \mathrm{~mW} / \mathrm{cm}^{3}$ appears feasible from a heat-removal standpoint for a practical manifolding arrangenent, whereas up to about $100 \mathrm{~mW} / \mathrm{cm}^{3}$ can be accommodated with many short helium flow paths. The nuclear heat load may be limited to lower values, however, to avoid unacceptable degradation of the critical current.

Talle 3. Nwelear beat capaluility for several coolles system config nations

\begin{tabular}{lccc}
\hline & \multicolumn{3}{c}{ Configuration } \\
\cline { 2 - 4 } & A & B & C \\
\hline Number of turns in coolant path & 4 & 1 & $1 / 2$ \\
Coolant path length, $m$ & 72 & 18 & 9 \\
Helium inlet temperature, $\mathrm{K}$ & 4.2 & 4.2 & 4.2 \\
Helium ou let temperature, $\mathrm{K}$ & 5.8 & 6.0 & 5.9 \\
Helium islet presure, atm & 9.0 & 8.0 & 10.0 \\
Helium outlet preasure, atm & 2.7 & 2.3 & 2.6 \\
Helium flow rate per channel, $8 / \mathrm{s}$ & 15 & 30 & 50 \\
Maximum nuclear heat, $\mathrm{mW} / \mathrm{cm}^{3}$ & 12 & 75 & 100 \\
\hline
\end{tabular}

\section{CONCLUSIONS}

Maximum achievable current densities have been developed using a $\mathrm{Nb}_{3} \mathrm{Sn}$ cable-inconduit type of conductor. The recommended current densities were established by including effects of peak conductor temperature, cooling path length, conductor strain, conduit load-carrying capability, and peak nuclear heating. With a single grade of conductor, the TFCX design specification winding current density of $3500 \mathrm{~A} / \mathrm{cm}^{2}$ at $10 \mathrm{~T}$ can be met using the Westinghouse LCP conductor with JBK-75 conduit, provided that conductor temperature is maintained below $4.5 \mathrm{~K}$. 
With respect to maximum permissible nuclear heat loads, it is found that for practical helium manifolding arrangements (e.g., winding three-in-hand, a flow path length of four turns is about $72 \mathrm{~m}$ ), approximately 10 to $12 \mathrm{~mW} / \mathrm{cm}^{3}$ may be tolerated purely from a beat-removal standpoint. For more complex manifolding arrangements (e.g., cooling one turn or one-half turn in regions of peak nuclear heat), up to about $100 \mathrm{~mW} / \mathrm{cm}^{3}$ becomes possible. However, these nuclear heat loads require conductor temperatures up to about $6 \mathrm{~K}$, which would degrade the critical current to the point where the design specification current densities could not be met. 


\section{APPENDIX A \\ MAGNITIOS AND STRUCTURAL ANALYSIS FORMALISM}

\section{INTRODUCTION}

This appendix describes the supporting magnetics and structural analysis for the present superconducting TF coil current density study.

The srord section discusses the assumptions made in the magnetics and structural analysis and describes the design criteria selected. The third section documents the equations used to size the winding cavity, evaluate the design-limiting stresses in the winding pack, and evaluate the maximum allowable quench pressure.

The magnetics and structural analysis routine has been programmed for an VMM-rC (see Appendix B).

\section{ASSUMPTIONS AND DESIGN CRITERIA}

Conice of Condector

The example problems considered in this study assume use of a forced-flow, cable-inconduit conductor. This type of conductor offers the best potential for high current density; pool-boiling conductors, as a group, typically operate at much lower current densities than do forced-flow conductors.

Most of the examples in this study assume that a single grade of conductor is used throughout the winding. Possible methods of grading forced-flow windirgs were considered, but it was concluded that several unresolved feasibility issues rendered grading of forcedflow windings an overly optimistic assumption for a near-term device such as TFCX-S.

While the practicality of graded forced-flow windings is debatable, the analysis routine described in the next section includes the capability to model graded windings in which the conductor conduit cross section is maintained in all grades but different currents are used in each grade.

\section{Conductor Current}

The conductor current is supplied as input data to the magnetics sizing routine. The conductor current is typically two-thirds to four-fifths of the critical current, with the critical current adjusted to include the effect of field level, strain level, operating temperature, and cooldown contraction properties of the conductor composite.

\section{Structural Conaiderations}

One of the factors that limits the current density is the need to provide enough steel in the winding to withstand the combination of the compressive winding load that propagates from turn to turn, plus the orthogonal tensile load resulting from dilation of the coil. This structural requirement can be design limiting, particularly at high fields ( $\geqslant 10 \mathrm{~T})$. Because of this requirement, several previous forced-flow TF and poloidal field (PF) designs done by the Fusion Engineering Design Center (FEDC) (FED-Baseline, forced-flow option of 
TFCX-S) have used a U-channel co-wound with the conductor. Use of any type of cowound structure lowers the a"erage winding pack current density.

Tests performed by MIT on arrays of conduits (without a co-wound U-channel) loaded in transverse compression indicate that epoxy impregnation of the array greatly increases the tolerable transverse compressive load. Without the potting, the turn-to-turn load must be borne by the conduit in bending the corner elbow. The MIT test results indicate inat potting material in the interstices between adjacent coaduits acts much as a fluid and transmits the turn-to-turn load in a direct compressive load path through the conduit walls. At the time of this writing, MIT was performing a finite-element analysis (using two-dimensional continuum elements) of the winding cross section to corroborate the test results. This more favorable load path offers the potential opportunity to eliminate the cowound U-channel, with an attendant increase in current density.

In view of the MIT test results, this study assumes use of an epoxy-impregnated array of cable-in-conduit conductors without co-wound U-channels. Although perhaps not obvious at the outset, the limiting loading condition on the conduit is found to be the combination of turn-to-turn compressive loading in the wall of the conduit plus the dila znal tensile load. The structural analysis oi the conduit also considers the quench pressure load, although this loading condition turns out not to be a design driver in this case.

The structural analysis of the conduit is in accordance with the established FEDC Magnet System structural criteria. In the present application, these criteria limit the algebraic difference of the dilational tensile stress and the transverse compressive stress in the conduit wall to two-thirds of yield strength or one-third of iltimate strength, whichever is less. Since the two stress components are of opposite sign, the stress limit is applied to the sum of the absolute values of the components. Application of stress limits to the maximum stress intensity (i.e., the maximum algebraic difference between principal stru_es in mutually orthogonal directions) is a standard structural design technique that follows from the well-known Tresca failure criterion for multiaxial stress states. Application of stress limits to stress intensities can be very different from application of the same limits to individual stress components.

\section{Conductor Conduit Fabrication}

The required conduit thickness is determined by the need to withstand loads that arise during quench and during normal magnet operation. On the other hand, manufacturing operations that must be carried out in the course of fabricating the conduit place a practical limit on the conduit thickness. Airco considers that $3 \mathrm{~mm}$ is the maximum jacket thickness that is practical with existing forming equiprnent. Furthermore, in view of Airco's experience in forming the 1.7-mm-thick jacket for the Wcstinghouse LCP conductor, members of the Westinghouse LCP team expressed the opinion that jacket thicknesses of much more than $1.7 \mathrm{~mm}$ would present a serious manufacturing problem.

Double-jacketing has been proposed as a possible alternative to thick conduit walls. However, this concept requires precise fit-up between the inner and outer jacket, and it has not yet been demonstrated that this fit-up can be achieved.

Consequently, conduit thicknesses have been limited to $3.0 \mathrm{~mm}$. Furthermore, in most examples the inside corner bend radius was set at twice the conduit wall thickness in order to limit bending strains during conduit-forming operations to $20 \%$. 


\section{MAGNETICS SIZING ROUTINE}

The magnetics sizing routine can model nultiple grades of forced-flow conductor. The routine assumes the cross-sectional dimensic. is of the condretor and conduit are the same in all grades. The operating current and maximum allowable field for each grade are supplied as input.

The radius $R_{N}$ at which the peal field $B_{N}$ must be developed is also specified. The amp-turns (AT) required to develop the peak field ar:

$$
\mathrm{AT}=\frac{B_{N} R_{N}}{\mu_{0} / 2 \pi} .
$$

The cotal area $A$ inside the conduit, as well as the conduit wall thickness $t_{w}$ inside surface curner bend radius $r_{b}$ and insulation wrap thickness $t_{i}$ are specified (Fig. 7). The transverse linear dimensions $L_{i}$ and $L_{0}$ are then

$$
L_{i}=\sqrt{A+(4-\pi) r_{b}^{2}}
$$

and

$$
L_{o}=L_{i}+2 t_{w}+2 t_{i}
$$

The TF coil case sidewall thickness $t_{s}$ and the bobbin ring and outer wall thickness $t_{b}$ are specified, as well as the number of TF coils $N_{c}$

The region of the TF coil winding assigned to conductor grade $j, j=1, \ldots, N$ is modeled as an annulus of outer radius $R_{j}$ and inner radius $\boldsymbol{R}_{j-1} . \boldsymbol{R}_{N}$ is specified, whereas $R_{N-1}, \ldots, R_{o}$ are to be determined. The combined winding area in all $N_{c}$ coils that is assigned to conductor grade $j$ is

$$
A_{j}=\pi\left(R_{j}^{2}-R_{j-1}^{2}\right)-2 N_{c} l_{s}\left(R_{j}-R_{j-1}\right)
$$

Starting with $j=N$ (high-field grade), $R_{j-1}$ is initially set equal to $R_{j}-L_{\sigma}$. The area $A_{j}$ is computed using Eq. (A.4). The number of conductor turns that will fit inside the area $A_{j}$ is taken as

$$
N_{j}=N_{c}\left(\frac{f A_{j} / N_{c}}{L_{o}^{2}}\right)
$$

where the parentheses indicate that the quantity therein is truncated to an integer. The term $f$ indicates the fraction of the total area $A_{N}$ that is actually filled by conductor. In 

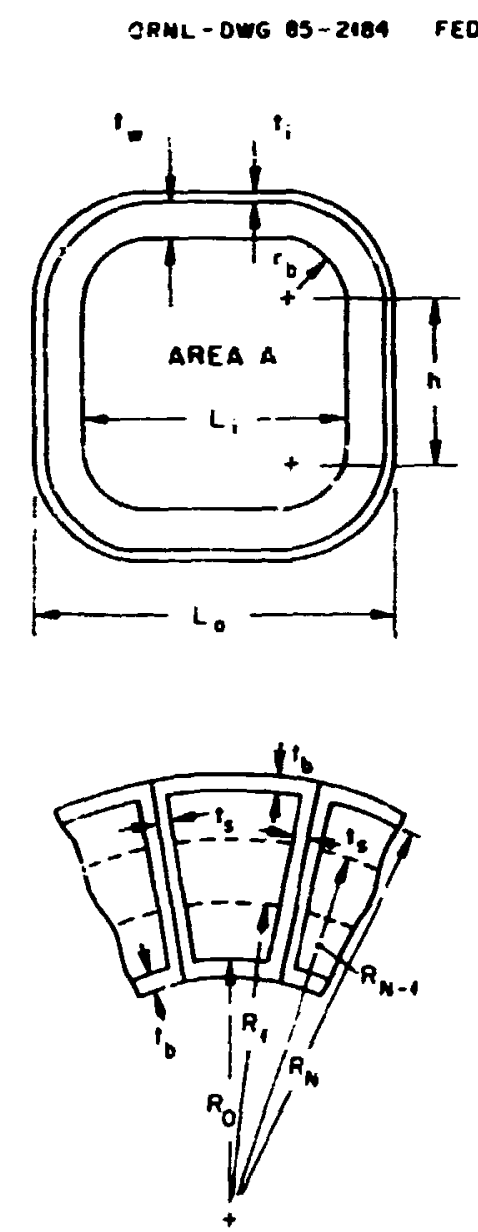

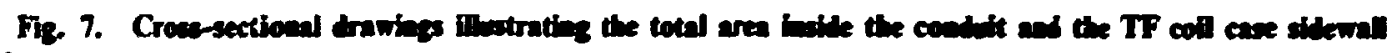
thickness.

lieu of doing a detailed winding layout, $f$ is supplied as input data, with $f=0.9$ built in as a representative default value.

The amp-turns in layer $j$ is

$$
(\mathrm{AT})_{j}=N_{j} I_{j}
$$

If $j>I$, the field at $R_{j-1}$ is computed as

$$
B_{j-1}=\left(\frac{\mu_{0}}{2 \pi}\right) \frac{\mathrm{AT}-(\mathrm{AT})_{N}-\ldots-(\mathrm{AT})_{j}}{R_{j-1}}
$$


If $B_{j-1}$ is greater than $\boldsymbol{B}_{j-1}^{*}$ (the maximum permissible field for grade $j-1$ ), $R_{j-1}$ is decremented by $L_{0}$ and Eqs. (A.4)-(A.7) are repeated until $B_{j-1} \leqslant B_{j-1}^{*}$, at which point the sizing of grade $j$ is completed. The index $j$ is then decremented by 1 , and Egs. (A.4)-(A.7) are repeated as many times as necessary to size the next grade in similar fashion.

For the lowest field grade $(j=1)$, instead of comparing $B_{j-1}$ to $B_{j-1}^{*}$, successive layers oi conductor are added until

$$
(\mathrm{AT})_{1}+\ldots+(\mathrm{AT})_{N} \geqslant \mathrm{AT}
$$

If the left side of Eq. (A.8) exceeds AT, the maximum field will ise exceeded at $\boldsymbol{R}_{\boldsymbol{N}}$, therefore, the conductor currents in all grades are scaled down by the factor

$$
S:=A T /\left[(\mathrm{AT})_{1}+\ldots+(\mathrm{AT})_{N}\right]
$$

After scaling by the factor $S$, the maximum permissible field may possibly be exceeded at one or more of the points $R_{N-1}, \ldots, R$. If such is the case, the permissible field at each of the nonconforming points is decreased by $1 \%$ and the entire sizing procedure repeated until there are no longer any nonconforming points.

The average winding pack current density is then

$$
\bar{j}=\mathrm{AT} /\left(A_{1}+\ldots+A_{N}\right)
$$

\section{STRUCTURAL ANALYSIS ROUTINE}

The centering force $(\mathrm{N} / \mathrm{m})$ on each TF coil is

$$
F_{c}=\sum_{j=1}^{N} \frac{\left(B_{j}+B_{j-1}\right)}{2} \frac{(\mathrm{AT})_{j}}{N_{c}}
$$

The transverse compressive stress in the conduit wall is

$$
\sigma_{c}=\frac{F_{c}}{\left(2 \pi R_{o}\right) / N_{c}} \frac{L_{o}}{2 l_{w}}
$$

The dilational force is estimated using the analytic expression for a constant tension shape (Fig. 8):

$$
F=F_{1}+F_{2}=\frac{B_{N}(\mathrm{AT}) R_{N}}{2 N_{c}} \ln \frac{R_{\text {out }}}{R_{\text {in }}}
$$


ORNL-OWG 85-2185 FED

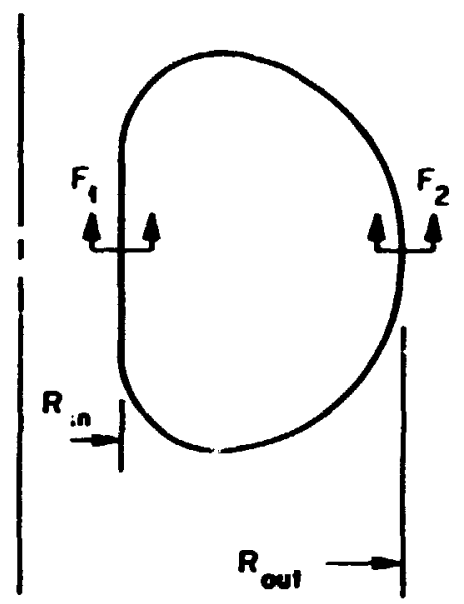

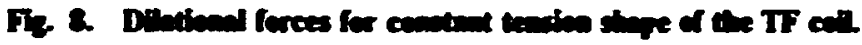

To allow for departure from constant tension shapes, the teasile force at the inside section is taken as

$$
F_{1}=0.55 F
$$

The dilational tensile stress is assumed to be shared between the coil case material and the conduit wall material in proportion to their respective cross-sectional arizas; this further assumes that both are made of the same material. The tensile stress in the conduit wall is,

$$
\begin{aligned}
& \sigma_{1}=F_{1} /\left(A_{\text {case }}+A_{\text {conduil }}\right), \\
& A_{\text {case }}=\frac{2 \pi l_{b}\left(R_{N}+R_{0}\right)}{N_{c}}+2 t_{s}\left(R_{N}-R_{0}\right) .
\end{aligned}
$$

and

$$
A_{\text {conduit }}=A_{j}-\frac{N_{1}+\ldots+N_{N}}{N_{c}}
$$


where $A_{f}$ is the cross-sectional area of a single conduit (Fig. 9):

$$
\begin{aligned}
A_{j} & =t_{w}\left[4 h+2 \pi\left(r_{b}+\frac{t_{w}}{2}\right]\right] \\
& =t_{w}\left(4 h+2 \pi r_{b}+\pi t_{w}\right),
\end{aligned}
$$

and

$$
h=L_{i}-2 r_{b} .
$$

Since $\sigma_{c}$ [Eq. (A.12)] is compressive and $\sigma_{\ell}$ [Eq. (A.15)] is tensile, the Tresca failure stress $\sigma_{e}$ is the sum of the absolute values:

$$
\sigma_{e}=\sigma_{c}+\sigma_{l}
$$

According to established structural criteria, $\sigma_{e}$ is limited to two-thirds of yield strength or one-third of ultimate strength, whichever is less.

The maximum allowable quench pressure is found by modeling the conduit as a square tube with rounded corners, subjected to a uniform internal pressure $p$. The pressure loading causes the square cross section to deform into a more nearly circular shape. The

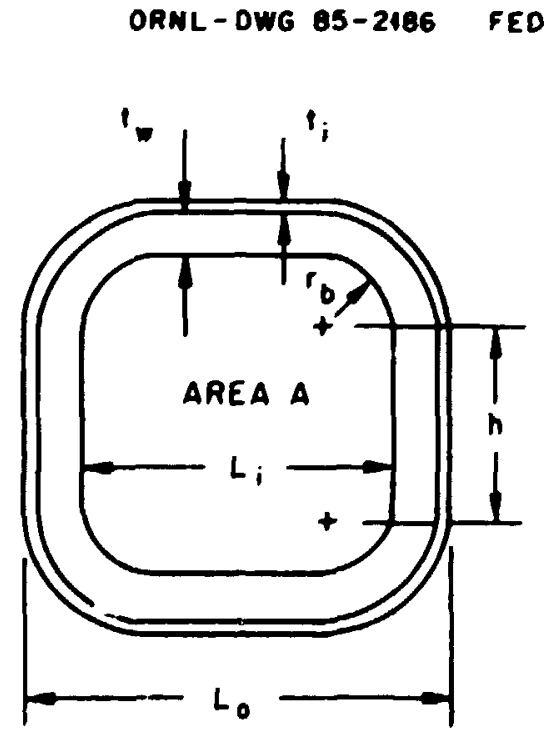

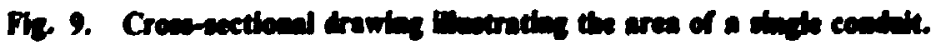


membrane and bending stresses both assume their peak values at the corner bend of the conduit. The membrane stress nay be calculated by inspection, whereas the bending stress is calculated per ref. 10.

The primary membrane stress is given by

$$
\sigma_{m}=p \frac{\left[\sqrt{2} L_{i}-2(\sqrt{2}-1) r_{b}\right]}{2 t_{w}} .
$$

The bending moment in the corner per ref. 10 is

$$
M=C p\left(L_{i}+t_{w}\right)^{2}
$$

where $C$ is a dimensionless coefficient that is a function of

$$
x=\frac{\left(r_{b}+\frac{t_{w}}{2}\right)}{\left(L_{i}+t_{w}\right)}
$$

P.Ad $a$ found by linear interpolation between the Table 4 values.

The bending stress (tensile at the inside surface) is found in terms of $M$ using conventional curved-beam theory as applied to a uniform rectangular cross section.

The distance that the neutral axis is displaced from the centroidal axis toward the center of curvature is

$$
\bar{y}=\frac{r_{b}+\left(t_{w} p\right)-t_{w}}{\ln \left(1+t_{w} / r_{b}\right)}
$$

Table 4. Coefricien $C$ is $x$

\begin{tabular}{ll}
\hline$x$ & \multicolumn{1}{c}{$C$} \\
\hline 0 & 0.0833 \\
0.1 & 0.0594 \\
0.2 & 0.0389 \\
0.3 & 0.0220 \\
0.4 & 0.0091 \\
0.5 & 0.0 \\
\hline
\end{tabular}


The distance from the neutral axis to the inside surface is

$$
h_{i}=\frac{t_{w}}{2-\bar{y}} .
$$

The bending stress at the inside surface is

$$
\sigma_{b}=\frac{M h_{i}}{t_{w} \bar{y} r_{b}}=\frac{C \cdot p\left(i_{i}+t_{w}\right)^{2} h_{i}}{t_{w} \bar{y} r_{b}} .
$$

In order to limit the membrane stress to the allowable $\sigma_{m}^{*}\left(2 / 3 S_{y}\right.$ or $1 / 3 S_{w n}$ whichever is less), $p$ must not exce $x p_{1}$, given by

$$
p_{1}=\frac{2 \sigma_{m}^{*} t_{w}}{\left[\sqrt{2}\left(L_{i}-2 r_{b}\right)+2 r_{b}\right]} .
$$

In order to limit the sum of membrane-pius-bending stress to the allowable $\sigma_{\text {mpb }}^{*}\left(S_{y}\right.$ oI $1 / 2 S_{u}$, whichever is lisss), $p$ must not exceed $p_{2}$, given bv

$$
p_{2}=\frac{\sigma_{m p b}^{\infty}}{\left|\frac{\sqrt{2}\left(l_{i}-2 r_{b}\right)+2 r_{b}}{2 t_{w}}+\frac{C\left(L_{i}+t_{w}\right)^{2} h_{i}}{t_{w} \bar{y} r_{b}}\right|} .
$$

For most practical cenduit-bend radii, $p_{2}$ is more restrictive than $p_{1}$. 


\section{APPENDIX B \\ MAGNETICS AND STRUCTURAL ANALYSIS ROUTTNE}

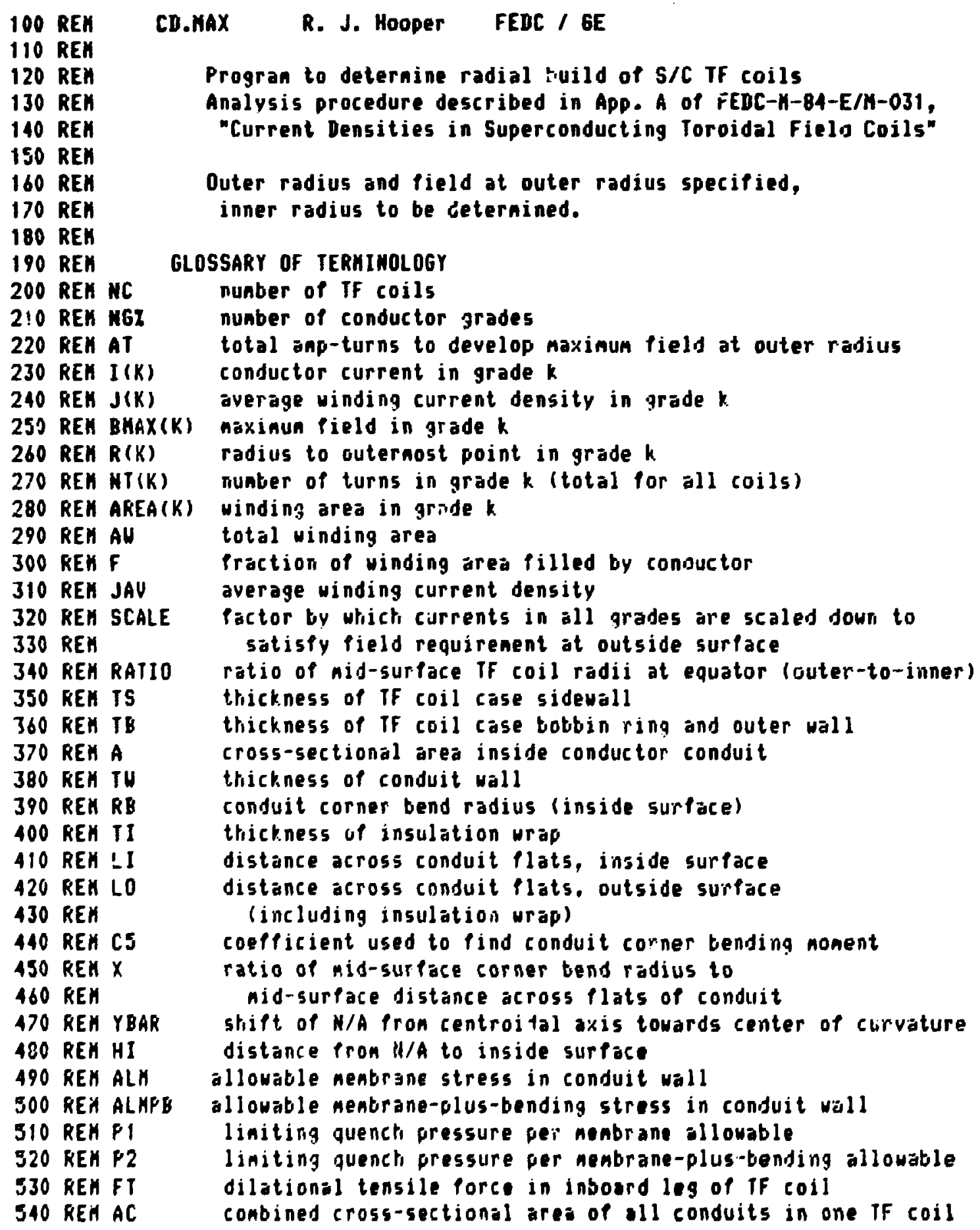




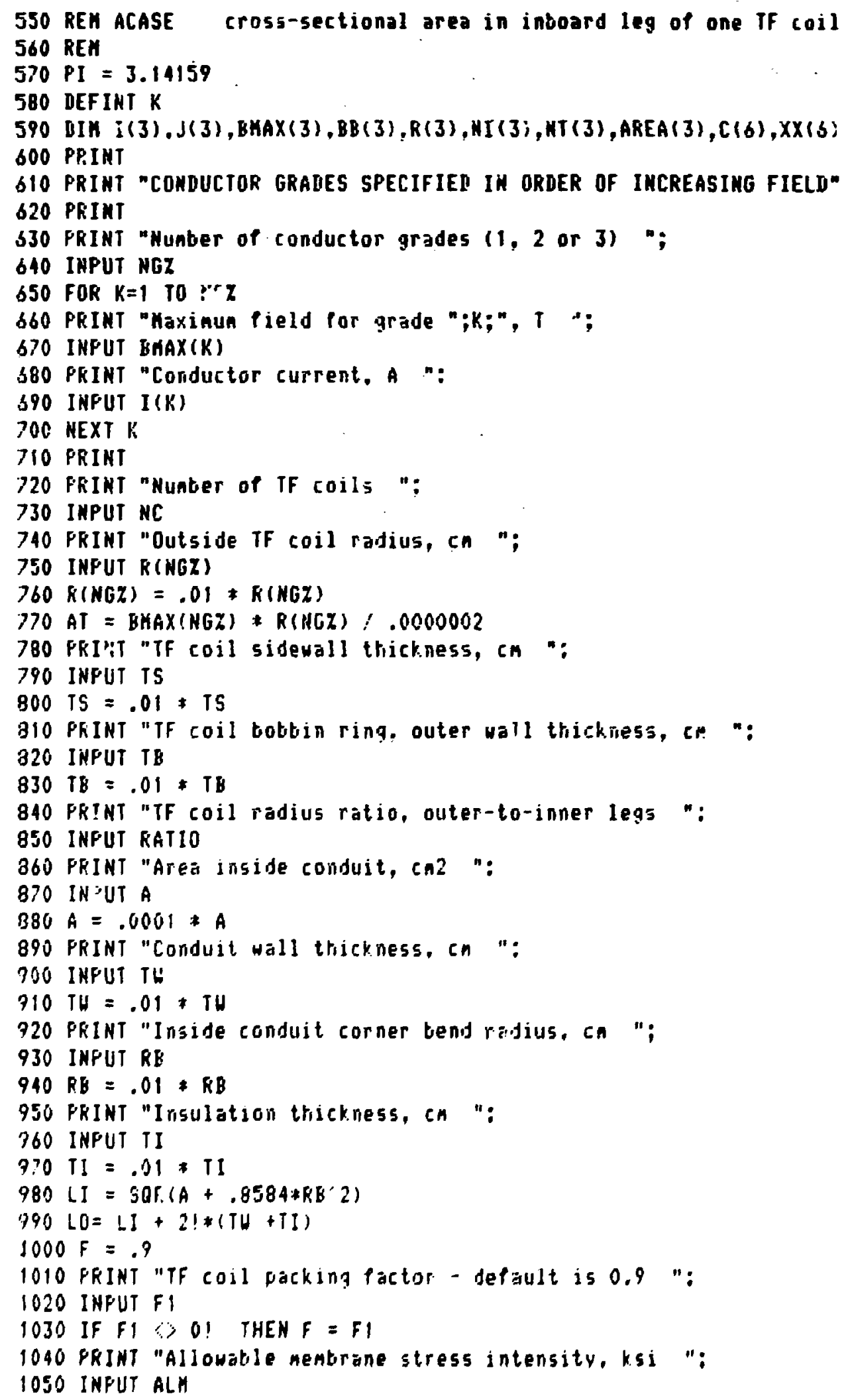




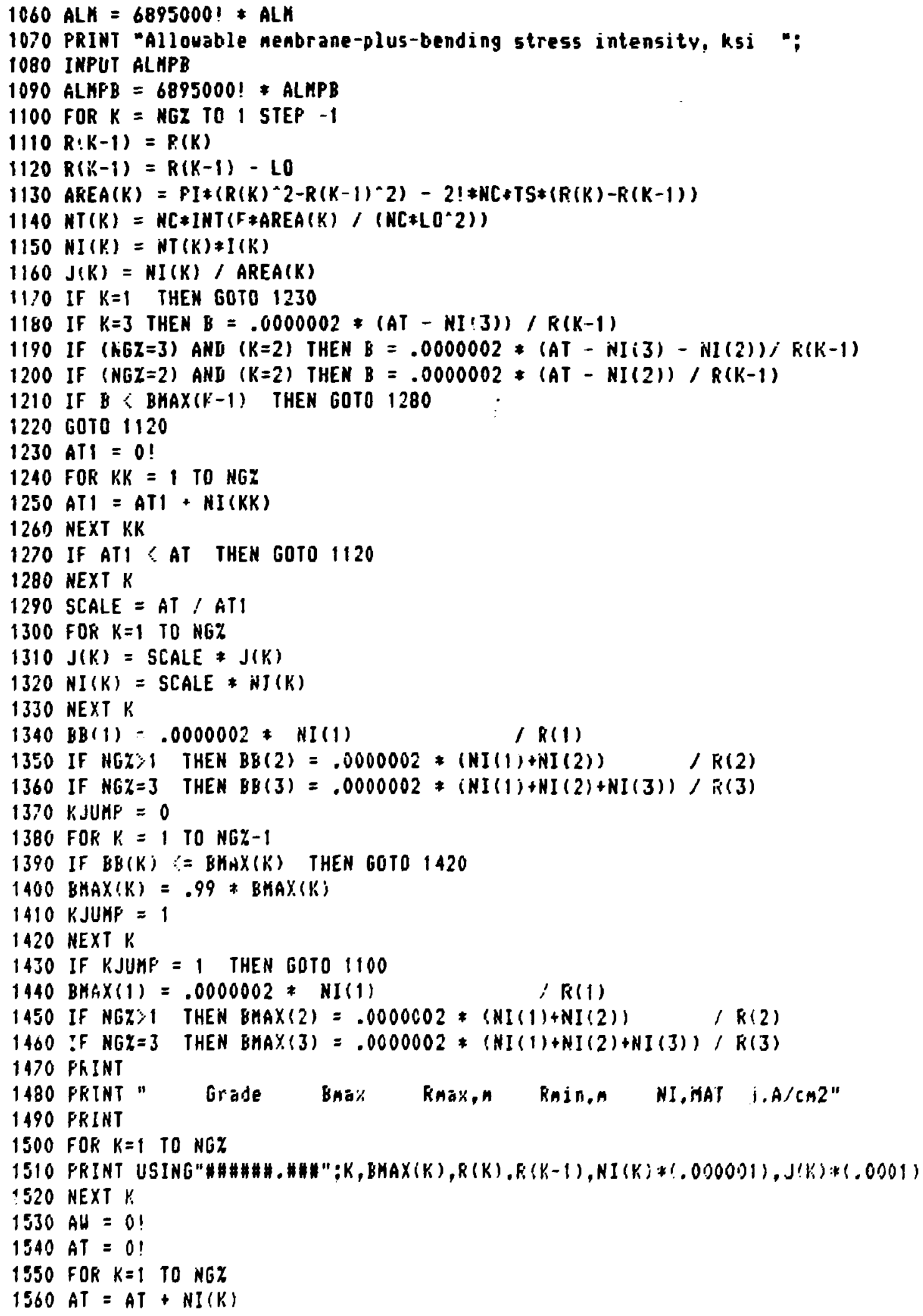




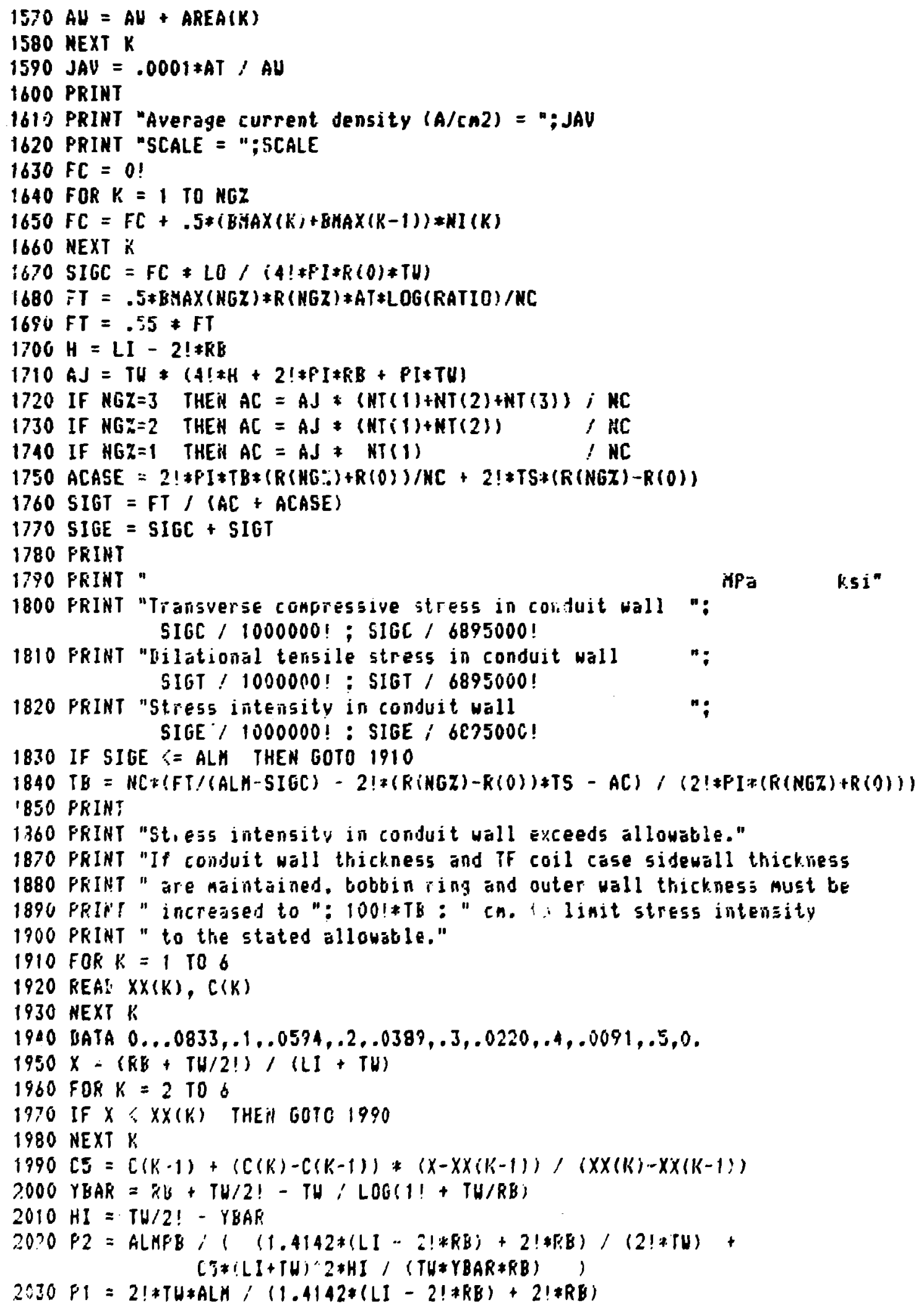


2040 PRINT

2050 IF P1 < P2 THEN GOTO 2090

2060 PRIMT "Allowatle quench pressure, ath. "i P2 / 101300!

2070 PRINT - (linited by nenbrane-plus-bending stress at inside surface)"

2080 GOTO 2110

2090 PRIKT "Allowable quench pressure, ath. "; P1 / 101300!

2100 PRIKT "(linited by mentrane stress in corner)"

2110 END 


\section{0}

\section{REFERENCES}

1. G. V. Sheffield and W. T. Reiersen, TFCX (Tokamak Fusion Core Experiment) Preconceptual Design Specification, Rev. 2, Princeton Plasma Physics Lab., June 15, 1984.

2. "Superconducting Magnet Coils $\mathrm{f}$ t the Large Coil Program," Westinghouse Electric Corp., ORNL Contract No. 22X-31747C, March 1980.

3. M. M. Steeves and M. O. Hoenig, "Experimental Parameter Study of Subsize $\mathbf{N b}_{3} \mathbf{S n}$ Cable-in-Conduit Conductors," IEEE Trans. Magn. 1\%(3) (1983).

4. P. A. Hudson, F. C. Yin, and H. Jones, "The Critical Current Density of Filamentary $\mathrm{Nb}_{3} \mathrm{Sn}$ ar - Function of Temperature and Magnetic Field," Clarendon Laboratory, Oxford srsity, November 1983.

5. M. M. : aves, M. O. Hoenig, and C. Z. Cyders, "Effects of Incoloy 903 and Tantalum Conduits on Critical Current in $\mathrm{Nb}_{3} \mathrm{Sn}$ Cable-in-Conduit Conductors," Adv. Cryog. Eng. 30, 883 (1984).

6. M. O. : Conig, M. M. Steeves, and C. J. Cyders, "Niobium-3-Tin Internally Cooled Cable Superconductor (ICCS) Technology I," presented at the MT-8 Magnet Conference, Grenoble, France, September 1983.

7. M. O. Hoenig, "Incoloy $\mathbf{9 0 3 / 9 0 5}$ as Sheathing Material for Cable-in-Conduit $\mathrm{Nb}_{3} \mathrm{Sn}$ Superconductors," MIT Magnet Laboratory unpublished memo.

8. "Superconducting Magnet Requirements for Intermediate-Scale, Long-Pulse Tokamaks," workshop summary presented at the U.S.-Japan Workshop, MIT Plasma Fusion Center, Sept. 17-19, 1984.

9. R. D. McCarty, "Thermophysical Properties of Helium-4 from 2 to $1500 \mathrm{~K}$ with Pressures to 1000 Atmospheres," NBS Technical Note 631, November 1972.

10. R. J. Roark, Formulas for Stress and Strain, 4th ed., p. 117. 
ORNL/FEDC-84/11

Dist. Category UC-20 c,d

\section{INTERNAL DISTRIBUTION}

1. T. G. Brown

2. J. Haines

3. P. N. Haubenreich

4-S. S. S. Kalsi

10. J. K. Johnson

11. D. C. Lousteau

12. M. S. Lubell

13. M. J. Saltmarsh

14. T. E. Shannon
15-16. Laboratory Records Department

17. Laboratory Records, ORNL-RC

18. Central Research Library

19. Document Reference Section

20. ORNL Patent Office

21. Fusion Energy Division Library

22. Fusion Energy Division Publications

Office

\section{EXTERNAL DISTRIBUTION}

23. M. A. Abdou, School of Elıgineering and Applied Science, 6288 Boelter Hall, University of California, Los Angeles, CA $\mathbf{9 0 0 2 4}$

24. C. A. Anderson, Westinghouse Electric Corporation, Advanced Energy Systems Division, P.O. Box 158, Madison, PA 15663

25. J. L. Anderson, CMB-3, Mail Stop 348, Los Alamos National Laboratory, P.O. Box 1663, Los Alamos, NM 87545

26. C. C. Baker, FPP/208, Argonne National Laboratory, 9700 South Cass Avenue, Argonne, IL 60439

27. D. S. Beard, Office of Fusion Energy, Office of Energy Research, Mail Stop G-256, U.S. Department of Energy, Washington, DC 20545

28. K. L. Black, Department E452, McDonnell Douglas Astronautics Company, P.O. Box 516, St. Louis, MO 63166

29. R. Botwin, C47-05, Grumman Aerospace Corporation, P.O. Box 31, Bethpage, NY 11714

30. W. B. Brigzs, McDonnell Douglas Astronautics Company, P.O. Box 516, St. Louis, MO 63166

31. J. N. Brooks, FPP/207, Argonne National Laboratory, 9700 South Cass Avenue, Argonne, IL 60439

32. S. C. Burnett, GA Technologles, Inc., P.O. Box 81608, San Diego, CA 92138

33. J. D. Callen, Department of Nuclear Engineering, University of Wisconsin, Madison, WI 53706

34. D. R. Cohn, MIT Plasma Fusion Center, 167 Albany Street, Cambridge, MA 02139 
35. J. W. Coursen, C36-05, Grumman Aerospace Corporation, P.O. Box 31, Bethpage, NY 11714

36. R. W. Conn, School of Chemical, Nuclear, and Thermal Engineering, Boelter Hall, University of California, Los Angeles, CA 90024

37. J. G. Crocker, EG\&G Idaho, P.O. Box 1625, Idaho Falls, ID 83401

38. G. R. Dalton, Department of Nuclear Engineering Science, Nuclear Science Center, University of Florida, Gainesville, FL 32611

39. R. C. Davidson, Massachusetts Institute of Technology, 77 Massachusetts Avenue, Cambridge, MA 02139

40. N. A. Davies, Office of Fusion Energy, Office of Energy Research, Mail Station G-256, U.S. Department of Energy, Washington, DC 20545

41. S. O. Dean, Director, Fusion Energy Development, Science Applications, Inc., 2 Professional Drive, Suite 249, Gaithersburg, MD 20760

42. J. F. Decker, Office of Fusion Energy, Office of Energy Research, Mail Stop G-256, U.S. Department of Energy, Washington, DC 20545

43. D. DeFreece, E451, Building 81/1/B7, McDonnell Douglas Astronautics Company, P.O. Box 516, St. Louis, MO 63166

44. J. N. Doggett, L-441, Lawrence Livermore National Laboratory, P.O. Box 808, Livermore, CA 94550

45. H. Dreicer, Division Leader, CTR, Los Alamos National Laboratory, P.O. Box 1663, Los Alamos, NM 87545

46. D. Ehst, Argonne National Laboratory, 9700 South Cass Avenue, Argonne, IL 60439

47. F. Farfaletti-Casali, Engineering Division, Joint Research Center, Ispra Establishment, 21020 Ispra (Varese), Italy

48. P. A. Finn, Fusion Power Program, Argonne National Laboratory, 9700 South Cass Avenue, Argonne, IL 60439

49. H. K. Forsen, Bechtel Group, Inc., Research \& Engineering, P. . Box 3965, Sar. Francisco, CA 94119

50. J. S. Foster, Jr., Building R4-2004, TRW Defense and Space Systems, I Space Park, Redondo Beach, CA 90278

51. T. K. Fowler, Associate Director for MFE, L-436, Lawrence Livermore National Laboratory, P.O. Box 808, Livermore, CA 94550

52. J. W. French, EBASCO Services, Inc., Forrestal Campus, CN-59, Princeton University, Princeton, NJ 08544

53. H. P. Furth, Director, Princeton Plasma Physics Laboratory, P.O. Box 451, Princeton, NJ 085:4

54. J. G. Gavin, Jr., President, A01-II, Grumman Aerospace Corporation, P.O. Box 31, Bethpage, NY 11714

55. G. Gibson, Westinghous= Electric Corporation, Advanced Energy Systems Division, P.O. Box 158, Madison, PA 15663

56. J. R. Gilleland, Manager, Fusion Project, GA Technologies, Inc., P.O. Box 81608 , San Diego, CA 92138

57. M. Y. Gohar, Argonne National Laboratory, 9700 South Cass Avenue, Argonne, IL 60439 
58. R. W. Gould, Department of Applied Physics, California Institute of Technology, Pasadena, CA 91109

59. M. W. Griffin, Department E236, McDonnell Douglas Astronautics Company, P.O. Box 516, St. Louis, MO 63166

60. C. R. Head, Office of Fusion Energy, Office of Energy Research, Mail Stop G-256, U.S. Department of Energy, Washington, DC 20545

61. C. D. Henning, Lawrence Livermore National Laboratory, P.O. Box 808, Livermore, CA 94550

62. J. J. Holmes, Westinghouse-Hanford Engineering Development Laboratory, P.O. Box 1970, Richland, WA 99352

63. D. Hwang, Princeton Plasma Physics Laboratory, P.O. Box 451, Princeton, NJ 08544

64. J. B. Joyce, Princeton Plasma Physics Laboratory, P.O. Box 451, Princeton, NJ 08544

65. R. A. Krakowsi, CTR-12, Mail Stop 641, Los Alamos National Laboratory, P.O. Pox 1663, Los Alamos, NM 87545

66. G. L. Kulcinski, University of Wisconsin, Department of Nuclear Engineering, Engineerir , Research Building, Room 439, 1500 Johnson Drive, Madison, WI 53706

67. D. L. Kummer, McDonnell Douglas Astronautics Company, P.O. Box 516, St. Louis, MO 63166

68. D. G. McAlees, Exxon Nuclear Company, Inc., 2101 Horn Rapids Road, Richland, WA 99352

69. W. Marton, Office of Fusion Energy, Office of Energy Research, Mail Station G-256, U.S. Department of Energy, Washington, DC 20545

70. L. G. Masson, EG\&G Idaho, Idaho National Engineering Laboratory, P.O. Box 1625, Idaho Falls, ID 83401

71. D. M. Meade, Princeton Plasma Physics Laboratory, P.O. Box 451, Princeton, NJ 08544

72. A. T. Mense, Building 107, Post B2, McDonnell Douglas Astronautics Company, P.O. Box 516, St. Louis, MO 63166

73. R. W. Moir, Lawrence Livermore National Laboratory, P.O. Box 808, Livermore, CA 94550

74. D. B. Montgomery, MIT Plasma Fusion Center, 167 Albany Street, Cambridge, MA 02139

75. A. E. Munier, Grumman Aerospace Company, P.O. Box 31, Bethpage, NY 11714

76. R. E. Nygren, FPP/207, Argonne National Laboratory, 9700 South Cass Avenue, Argonne, IL 60439

77. T. Ohkawa, GA Technologies, Inc., P.O. Box 81608, San Diego, CA 92138

78. J. A. O"Toole, Plasma Physics Laboratory, Building I-P, Room 8A, James Forrestal Campus, P.O. Box 45I, Princeton, NJ 08544

79. R. R. Parker, Francis Bitter National Magnet Laboratory, 170 Albany Street, Cambridge, MA 02139

80. B. Pease, Culham Laboratory, Abingdon, Oxfordshire OX14 3DB, United Kingdom

81. M. Pelovitz, Princeton Plasma Physics Laboratory, P.O. Box 451, Princeton, NJ 08544 
82. F. W. Perkins, Princeton Plasma Physics Laboratory, P.O. Box 451, Princeton, NJ 08544

83. M. Porkolab, Massachusetts Institute of Technology, 77 Massachusetts Avenue, Cambriage, MA 02139

84. D. E. Post, Princeton Plasma Physics Laboratory, P.O. Box 451, Princeton, NJ 08544

85. L. K. Price, Department of Energy, Oak Ridge Operations, P.O. Box E, Oak Ridge, TN 37831

86. R. E. Price, Office of Fusion Energy, Office of Energy Research, Mail Station G-256, U.S. Department of Energy, Washington, DC 20545

87. F. A. Puhn, GA Technologies, Inc., P.O. Box 81608, San Diego, CA 92138

88. J. Purcell, GA Technologies, Inc., P.O. Box 81608, San Diego, CA 92138

89. R. V. Pyle, University of California, Lawrence Berkeley Laboratory, Berkeley, CA 94720

90. J. M. Rawls, GA Technologies, Inc., P.O. Box 81608, San Diego, CA 92138

91. H. P. Furth, Princeton Plasma Physics Laboratory, P.O. Box 451, Princeton, NJ 08544

92. M. Roberts, Office of Fusion Energy, Office of Energy Research, Mail Stop G-256, U.S. Department of Energy, Washington, DC 20545

93. J. D. Rogers, Los Alamos National Laboratory, P.O. Box 1663, Los Alamos, NM 87545

94. M. L. Rogers, Monsanto Research Corporation, Mound Laboratory Facility, P.O. Box 32, Miamisburg, OH 45342

95. M. N. Rosenbluth, RLM 11.218, Institute for Fusion Studies, University of Texas, Austin, TX 78712

96. P. H. Rutherford, Princeton Plasma Physics Laboratory, P.O. Box 451, Princeton, NJ 08544

97. J. A. Schmidt, Princeton Plasma Physics Laboratory, P.O. Box 451, Princeton, NJ 08544

98. J. Schultz, MIT Plasma Fusion Center, 167 Albany Street, Cambridge, MA 02139

99. F. R. Scott, Electric Power Research Institute, P.O. Box 10412, Palo Alto, CA 94304

100. G. Sheffield, Princeton Plasma Physics Laboratory, P.O. Box 451, Princeton, NJ 08544

101. D. Smith, Materials Science Division, Argonne National Laboratory, 9700 South Cass Avenue, Argonne, IL 60439

102. L. Southworth, GA Technologies, Inc., P.O. Box 81608, San Diego, CA 92138

103. W. M. Stacey, Jr., Georgia Institute of Technology, School of Nuciear Engineering, Atlanta, GA 30332

104. E. Stern, Grumman Aerospace Corpuration, CN-59, Forrestal Campus, Princeton, NJ 08544

105. P. M. Stone, Office of Fusion Energy, Office of Energy Research, Mail Station G-256, U.S. Department of Energy, Washington, DC 20545

106. 1. N. Sviatoslavsky, Room 33, Engineering Research Building, 1500 Johnson Drive. University of Wisconsin, Madison, WI 53706 
107. R. E Tatro, Manager, Energy Systems, M.Z. 16-1070, General Dynamies-Convair Division, P.O. Box 80847, San Diego, CA 92138

108. F. Thomas, B-20-5, Grumman Aerospace Corporation, Bethpage, NY 11714

109. K. I. Thomassen, Lawrence Livermore National Laboratory, P.O. Box 808 , Livermore, CA 94550

110. R. J. Thome, Francis Bitter National Magnet Laboratory, 170 Albany Street, Cambridge, MA 02139

111. C. Trachsel, McDonnell Douglas Astronautics Company, P.O. Box 516, St. Louis, MO 63166

112. A. W. Trivelpiece, Office of Fusion Energy. Office of Energy Research, Mail Station G-256, U.S. Department of Energy, Washington, DC 20545

11 3. L. R. Turner, Fusion Power Program, Argonne National Laboratory, 9700 South Cass Avenue, Argonne, IL 60439

114. E. H. Valeo, Princeton Plasma Physics Laboratory, P.O. Box 45I, Princeton, NJ 08544

115. R. Varma, Physical Research Laboratory, Navrangpura, Ahmedabad, India

116. K. E. Wakefield, Princeton Plasma Physics Laboratory, P.O. Box 451, Princeton, NJ 08544

117. J. C. Wesley, GA Technologies, Inc., P.O. Box 81608, San Diego, CA 92138

i 18. H. Willenberg, Mathematical Sciences Northwest, Inc., P.O. Box 1887, Bellevue, WA 98009

119. J. E. C. Williams, Francis Bitter National Magnet Laboratory, 170 Albany Street, Cambridge, MA 02139

120. H. H. Yoshikawa, W/A-62, Hanford Engineering Development Laboratcry, F.O. Box 1970, Richland, WA 99352

121. K. M. Young, Princeton Plasma Physics Laboratory, P.O. Box. 151, Princeton, NJ 08544

122. N. E. Young, EBASCO Services, Inc., Princeton Plasma Physics Laboratory, P.O. Box 451, Princeton, NJ 08544

123. Bibliothek, Max-Planck-Institut fur Plasmaphysik, D-8046 Garching bei Munchen, Federal Republic of Germany

124. Bibliothek, Institut fur Plasmaphysik, KFA, Postfach 1913, D-5170 Julich, Federal Republic of Germany

125. Library, Centre de Recherches en Physique des Plasmas, 21 Avenue des Bains, 1007 Lausanne, Switzerland

126. Bibliotheque, Service du Confinement des Plasmas, CEA, B.P. No. 6, 92 Fontenayaux-Roses (Seine), France

127. Documentation S.I.G.N., Department de la Physique du Plasma et de la Fusion Controlec, Association EURATOM-CEA. Centre d'Etudes Nucleaires, B.P. 85, Centre du Tri, 38041 Grenoble, France

128. Library, Culham Laboratory, UKAEA, Abingdon, Oxfordshire, OX14 3DB, England

129. Library, FOM Instituut voor Plasma-Fysica, Rijnhuizen, 14 Edisonbaan, Jutphaas, The Netherlands 
130. Library, Institute for Plasma Physics, Nagoya University, Nagoya 464, Japan

13L. Library, International Centre for Theoretical Physics, Trieste, Italy

132. Library, JET Joint Undertaking, Abingdon, Oxfordshire, OX14 3DB, England

133. Library, Laboratorio Gas Ionizzati, CP 00044 Frascati, Rome, Italy

134. Plasnua Research Laboratory, Australian National Laboratory, P.O. Box 4, Canberra, ACT 2000, Australia

135. Thermonuclear Library, Japan Atomic Energy Research Institute, Tokai, Naka, Ibaraki, Japan

136. Library, Plasma Physics Laboratory, Kyoto University, Gokasho, Uji, Kyoto, Japan

137. Office of the Assistant Manager for Energy Research and Development, Department of Energy, Oak Ridge Operations, Oak Ridge, TN 37830

138-327. Given distribution as shown in TID-4500, Magnetic Fusion Energy (Category Distribution UC-20 c,d: Reactor Materials and Fusion Systems) 